Norma M. Hussey

\title{
A New Hope for the Symbolic, for the Subject
}

\section{Symbolization and ontology}

Tradition is the old world of castes, nobilities, religious obligation, ... local mythology, the submission of women, the father's absolute power over his children, and the official division between a small group of rulers and a condemned mass of toilers, in which the differences inherent to human life were regulated and symbolized in a hierarchical form. The most important binaries, like old and young, men and women, ... commoners and nobles, town and countryside - were all addressed (in language, in mythologies, in ideologies, and in the established religious models) by recourse to ordered structures setting everyone's place in a set of overlapping hierarchical systems. ${ }^{1}$

From the philosophical writings of Alain Badiou (illuminated by the mathematical ontology) it is recognized here that the hierarchical symbolization of 'tradition' found its guarantee, at the abstract level, in the supposition that beyond the multiple, the one is. In other words, the ontological basis for the hierarchical form of the traditional symbolic assumes the being of the one, and relies on it for the "normative power" of its deployment. As such, it is a symbolic based on finitude, which means that (in the mathematical ontology) it "resides within the elementary immanence of ... finite ordinals." 3 This is the case whether the one be finite or infinite. For instance, "Christian monotheism, despite its designation of God as infinite, does not immediately and radically rupture with Greek finitism" - it can be based on a thinking in which being as such "remains essentially finite;" the assumption of an infinite one does not yet break with the finite,

1 Alain Badiou, "True and False Contradictions of the Crisis", trans. David Broder, Verso blog, May 29, 2015. Emphasis added.

2 Alain Badiou, Theoretical Writings, trans. Ray Brassier and Alberto Toscano, Bloomsbury Academic, London and New York 2014, p. 44.

3 Alain Badiou, Being and Event, trans. Oliver Feltham, Continuum, London and New York 2007, p. 160. 
because it is still "hierarchically representable as beyond [or unknowable], yet deducible from," the finite world. ${ }^{4}$ According to Badiou, the onto-theological device - trying to save truth - pays the price of the absolute transcendence of the one, thereby subordinating finite multiplicities to the formal authority of the One-infinity that has often been called God. ${ }^{5}$

Modernity is effectively a break with tradition. In barely three centuries, this break with the world of tradition has swept aside forms of organization that had lasted for millennia. When this break takes a bourgeois, capitalist form, it opens up a gigantic crisis of humanity's symbolic organization. It does not in fact propose any active new symbolization, but only the brutal, independent play of the economy: the neutral, a-symbolic reign of what Marx called "the icy water of egotistical calculation.”6

It could be said that the breakdown of the traditional symbolic corresponds to modern ontological confusion owing to the death of God, 7 i.e. the infinite One. Modernity - in a world structured by globalized capitalism - has revealed that being is essentially multiple; it has exposed the one as pure semblance, and therefore ruined the supposition on which the hierarchical symbolic depends. In his Manifesto for Philosophy, Badiou writes that

The only thing we can and must welcome within Capital [is that]: it exposes the pure multiple as the foundation of presentation; it denounces every effect of One as a simple, precarious configuration ... To think over and above Capital ... we must still have as a departure point what it has revealed: Being is essentially multiple. ${ }^{8}$

\section{Symbolization and subjective orientation} the one as un-credible. But freedom from hierarchy, from subordination to the

$4 \quad$ Ibid, p. 142.

5 Badiou, as reported by Jana Berankova in "The Immanence of Truths: the Absolute between the Singular and the universal", Presentation at the International Conference “Thinking the Infinite”, April 11, Prague 2018.

6 Badiou, "True and False Contradictions of the Crisis". Emphasis added.

7 Badiou, Theoretical Writings, pp. 27-30.

8 Alain Badiou, Manifesto for Philosophy, trans. Norman Madarasz, SUNY Press, Albany, New York 1996, pp. 56-57. 
normative power of the one, without symbolic replacement, "creates a subjective crisis ... one of whose most remarkable aspects is the extreme and growing difficulty that young people in particular face finding themselves a place in this new world." Disorientation arises with the breakdown of symbolization, i.e. with the lack of a common understanding of the symbolic organization. Perhaps this is why the theme of the subject has been a constant for modernity.

Faced with the crisis of humanity's symbolic organization (and the associated crisis of general subjective disorientation) some would have us believe that there is no crisis, and that there is nothing better than this liberal 'democratic' model of freedoms weighed down by the neutrality of market calculations. This is Western capitalism's a-symbolic vision, which creates monstrous inequalities and pathogenic upheavals; under the auspices of 'freedom' in the a-symbolic reign, exploitation replaces the oppressions of hierarchy, and often inspires the reactive desire to return to the traditional hierarchical symbolization..$^{10}$

With respect to the break with tradition then, the subjective orientations of modernity range from the embrace of this liberal a-symbolic model of freedoms (especially by the rich), to the reactive desire to return to the traditional symbolization (especially by the ex-privileged), and in the wider context of general disorientation, from imaginary utopianism to hopeless nihilism. But there is another subjectivity which, recognizing the non-being of the one and the unavoidable break with tradition, is convinced that a non-hierarchical symbolization is possible and that it must be invented, i.e. "an egalitarian symbolization that restructures differences - [recognized of equal subjective right] - based on a total sharing of resources." ${ }^{1_{1}}$

\section{A new symbolic requires a coherent ontological referent}

From reading Badiou, it is my understanding that a symbolic (defined as a universal structure encompassing the entire field of human action and existence) $)^{12}$ can only be based (contrary, it would seem, to Lacan) on a credible thinking of being as such, i.e. a stable and consistent ontology. The normative power of an

9 Badiou, "True and False Contradictions of the Crisis".

10 Ibid.

11 Ibid.

12 Encyclopedia.com, Symbolic, the (Lacan), available at: https://www.encyclopedia. com>psychology $>$ symbolic-lacan 
assumed one (finite or infinite) sustained the hierarchical symbolic for millennia, but such an assumption is no longer credible - it has been exposed as pure semblance, and being is revealed as essentially multiple. If all is multiple, is a symbolic even possible? That is, a symbolic which recognizes the non-being of the one and therefore cannot rely on the deployment of its normative power, as such a non-hierarchical and therefore egalitarian symbolic? It would at least require a coherent, i.e. stable and consistent, ontology of multiplicity.

\section{An ontology of multiplicity}

The thesis of Alain Badiou which equates ontology with mathematics ${ }^{13}$ is underscored by the philosophical decision that being, or what we can think under the name of 'being,' is composed of pure multiplicities, and that "the one is not," be it the one of an Idea (Plato), or a God, or Presence, or any-one; "the one exists solely as operation." ${ }^{14}$ Since the axiomatic system of mathematical set theory delivers the multiple without implying the being of the one, ${ }^{15}$ Badiou adopts it as the thinking of being as such (ontology). Set theory is the area of modern mathematics devoted to the study of infinity; mathematics thinks (infinite) multiplicities in the form of the notion of a (infinite) set. ${ }^{16}$ It is based on a formal axiom system called ZFC (Zermelo-Fraenkel system with the axiom of choice). Quantitative infinity is not deducible from finitude, but is authorized solely by the axioms of mathematical set theory. ${ }^{17}$ It is by recognition of the mathematical existence of quantitatively distinct infinite multiples, that the ruin of the being of the infinite one is achieved. ${ }^{18}$ This thorough-going rationalization of actual infinities (as opposed to a transcendent one) teaches us that there is no reason to confine thinking within the ambit of finitude because we can have access to a rational, secular thinking of infinity. ${ }^{19}$ Mathematical ontology (i.e. set theory) is the proposal of an infinite ontology which is, finally, a radical rupture with the finitism of tradition, and in which "the finite is qualified as a region of being, a minor form of the latter's presence."2o

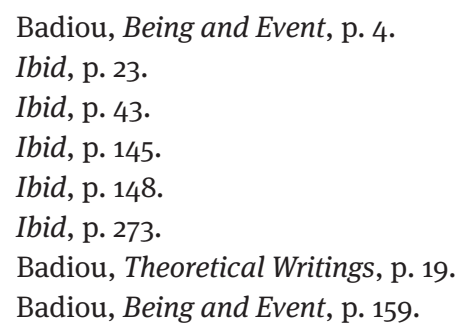


Badiou, in fact, proposes the universe of set theory - conventionally denoted by $\mathrm{V}$ - as an absolute ontological referent, where $\mathrm{V}$ can be said "to formalize ... the place ... of everything that can be constructed by axioms." ${ }^{21}$ He argues that "the absoluteness of the thinking of the pure multiple, in the atheistic takeover from monotheism ... is feasible." ${ }^{22}$

\section{But is it a coherent theory?}

In Being and Event (1988), ${ }^{23}$ Badiou described the then prevailing situation of ontology (set theory), with all of its intricacies and its metaontological implications. In particular, he highlighted the impasse concentrated in the continuum problem which, as Paul Cohen established in 1963, is undecidable from the contemporary ZFC axiomatic. Since then, the formal axiom system itself has been in crisis - which challenges the very conception of mathematical infinity, ${ }^{24}$ together with the credibility of set theory as a consistent ontology. It doesn't auger well for the invention of an egalitarian symbolic which can only be based on an ontology of the multiple, if that ontology is inconsistent or uncredible. The prevailing incoherence of the mathematical ontology underscores a contemporary deficit of symbolization which, in turn, yields confusion and conflict in terms of subjective orientation.

But something momentous is happening right now in set theory, in response to the recent surprise discovery now encapsulated in the universality theorem (see later); a new axiom, conjectured as yet, promises to resolve the crisis of its formalization, ${ }^{25}$ and achieve the pass of the impasse. The consequent realization of a coherent set theory - a stable and consistent ontology of multiplicity - would suggest that an egalitarian symbolization is possible, i.e. a modern symbolic which receives its guarantee solely, but transparently, in its mathematical consistency. Indeed, "mathematics is the only discourse in which one has a com-

${ }^{21}$ Acheronta Movebo (Badiou), "Towards a New Thinking of the Absolute”, Crisis and Critique 1 (2/2014), p. 12. Badiou was one of the contributors to this journal as part of the anonymous collective Acheronta Movebo.

22 Ibid., p. 21.

23 The original edition of Being and Event, i.e. Badiou, L'Être et L'Événement, Éditions du Seuil, Paris, was published in January 1988.

24 W. Hugh Woodin, “Generalizing Gödel's Constructible Universe: Ultimate L”, Presentation at the IMS Graduate Summer School in Logic, National University Singapore, June 2018.

25 W. Hugh Woodin, "In Search of Ultimate-L, the $19^{\text {th }}$ Midrasha Mathematicae Lectures", The Bulletin of Symbolic Logic 23 (1/2017), p. 2. (DOI:10.1017/bsl.2016.34). 
plete guarantee and a criterion of the truth of what one says, to the point that this truth is unique inasmuch as it is the only one ever to have been encountered which is fully transmissible." ${ }^{26}$

This remarkable development in set theory, led by W. Hugh Woodin, ${ }^{27}$ offers hope for the pursuit of a new symbolic in a modern age of actual infinity, and a consequent resolution of the general subjective disorientation which arises from our current crisis of symbolization.

The premise here, then, is that the process for the articulation of a coherent and transmissible ontology on which to ground an egalitarian symbolic has already begun; it originated with the Cantorian inventions of set theory and quantitative infinity, but it is still undergoing development as the contemporary set theoretic axiom system (ZFC) is not yet stable/complete.

\section{Set theory - historical development}

The saga surrounding the development of set theory over the past 150 years - its splits, its advances, its dramatic crises - reflects the extreme difficulty of invention of an ontology of multiplicity which is not in the least intuitive as it depends on complex mathematical reasoning and innovation for the thinking and comparison of distinct quantitative infinities. Mathematical infinity is a counter-intuitive concept, even at its simplest level, for instance "the infinite set of even numbers $\{2,4,6, \ldots\}$ can be placed in a one-to-one correspondence with all counting numbers $\{1,2,3, \ldots\}$, indicating that there are just as many evens as there are odds-and-evens, ${ }^{28}$ therefore we cannot rely on intuition, but require the patient and painstaking work of mathematical rigor, in order to understand it. The development of set theory also seems (almost uncannily) to have mirrored the general underlying situation in the social and political world over the same period (see below).

26 Badiou, Being and Event, p. 9. Emphasis added.

27 W. Hugh Woodin is the mathematical set theorist leading the remarkable developments in set theory referenced throughout this article, at Harvard University since 2014, and before that at the University of California, Berkeley.

28 Natalie Wolchover, “To Settle Infinity Dispute, a New Law of Logic”, quantamagazine.org, November 26, 2013 (reprinted on ScientificAmerican.com, December 3, 2013). 
The nine axioms of ZFC were laboriously developed around the turn of the $20^{\text {th }}$ century, thereby putting Cantor's still partly intuitive theory of sets on a secure axiomatic (or non-intuitive) footing. ${ }^{29}$ They accord with the iterative conception of sets as cumulative hierarchies, where sets are constructed by a combination of axiomatically prescribed procedures in successive steps from an assumed foundational empty set $\emptyset$, and the sets accumulate - hence 'cumulative.' The universe of sets $\mathrm{V}$ (as formalized by ZFC) is calibrated by the ordinals through the definition of the cumulative hierarchy of sets, ${ }^{30}$ in which the successor step is obtained by the power-set (i.e. the set of all subsets) of the preceding set. According to Badiou, the ordinals - as the ontological schema of natural multiplicity - "say that nothingness is a form of natural being [the empty set $\emptyset$ being an ordinal, and therefore a natural multiple], and that the infinite, far from being retained in the One of a God, is omnipresent in nature, and beyond that, in every situation-being." ${ }^{31}$

\section{Constructibility and conservatism}

Set theory was tentatively concluded with a tenth axiom, i.e. Kurt Gödel's axiom of constructibility (1938), which asserts that the universe of sets $V$ is the constructible universe L, i.e. V = L. Gödel's definition of L arises from restricting the successor step in the definition of the cumulative hierarchy to the constructible power-set (also called the definable power-set), which is the set of all subsets of the preceding set such that each subset is logically definable (in the set structure) from parameters in the set. ${ }^{32}$

29 Peter Hallward, “On the development of Transfinite Set Theory”, in Peter Hallward, $B a$ diou: A Subject To Truth, University of Minnesota Press, Minnesota 2003, p. 337. He also notes that Cantor's own position was anti-axiomatic.

30 The cumulative hierarchy of sets $\mathrm{V}$, is the collection of sets $\mathrm{V}_{\alpha}$ indexed by the class of ordinal numbers. For each ordinal $\alpha$, a set $V_{\alpha}$ is defined by induction on $\alpha$ as follows: $1 . V_{o}=$ $\emptyset$, 2. (Successor step) $V_{\alpha+1}=P\left(V_{\alpha}\right)$, the power-set of $V_{\alpha}$, 3. (Limit step) If $\alpha$ is a limit ordinal, then $\mathrm{V}_{\alpha}=\mathrm{U}\left\{\mathrm{V}_{\beta} \mid \beta<\alpha\right\}$, the union of all the V-stages so far.

${ }^{31}$ Alain Badiou, Number and Numbers, Polity Press, Cambridge UK and Malden USA 2008, p. 84 .

32 W. Hugh Woodin, "The Transfinite Universe”, in Kurt Gödel and the Foundations of Mathematics. Horizons of Truth, ed. M. Baaz, C. H. Papadimitriou, H. W. Putnam, D. S. Scott, and C. L. Harper Jr., Cambridge University Press, Cambridge 2011, pp. 449-471. 
Gödel's axiom “does provide a clear conception of the universe of sets V," 33 but as a minimal statement about the universe of sets (because if the set is infinite and the axiom of choice holds, then the definable power-set is never the set of all subsets of the set) ${ }^{34}$ it was never fully embraced as a true axiom for set theory. ${ }^{35}$ In addition, the constructible universe cannot accommodate the large cardinals in the higher infinite which, although unprovable from ZFC, are now considered to be genuine..$^{36}$ (Since the existence of such a set cannot be proven on the basis of ZFC, it has to form the object of a new axiom. What is then at stake is an axiom of infinity, stronger than that of ZFC which guarantees only the existence of a limit ordinal, ${ }^{37}$ i.e. a large cardinal axiom stating that there exists a cardinal (or perhaps many of them) with some specified large cardinal property. Such axioms appear to occur in strict linear order by consistency strength, thus forming the large cardinal hierarchy. A measurable cardinal is a relatively 'small' large cardinal, i.e. it is low in the hierarchy $3^{38}$ ) By Scott's theorem (1961), there are no measurable cardinals in the constructible universe and therefore no stronger large cardinals either. ${ }^{39}$ As such, $\mathrm{V}=\mathrm{L}$ "severely limits the nature of infinity."40

It could be said that Gödel's constructible universe represents a first attempt at an abstract referent for an egalitarian symbolic, in that it does yield a model for ZFC, i.e. a stable and consistent framework (albeit restricted) for an ontology of multiplicity. It is a universe for all ordinals (i.e. natural multiplicities) indicating that "the infinite is omnipresent in nature," but beyond that (i.e. with respect to non-natural multiplicities) it has nothing to say. As such it may be considered as a natural ontology, but it doesn't account for every situation-being. Its mathematical experimentation coincided with the period of social and political conservatism of the 1940's and '50's, which is not to suggest that Gödel was re-

33 Ibid.

34 W. Hugh Woodin, "Strong Axioms of Infinity and the Search for V", in Proceedings of the International Congress of Mathematicians, Hyderabad, India 2010.

35 Woodin writes: "We know that Gödel [himself] rejected the axiom V = L", in "The Transfinite Universe”.

36 Woodin, “Generalizing Gödel’s Constructible Universe: Ultimate L”.

37 Badiou, Being and Event, p. 513.

38 Colin J. Rittberg, "How Woodin Changed his Mind: New Thoughts on the Continuum Hypothesis”, Archive for History of Exact Sciences 69 (2/2015), pp. 125-151.

39 Ibid.

$4^{0}$ Woodin, as quoted by Wolchover in “To Settle Infinity Dispute, a New Law of Logic”. 
sponsible for that period of conservatism but, perhaps, that his work explains the abstract thinking behind what was going on at the time.

In The Immanence of Truths,,$^{41}$ Alain Badiou claims that we (still) live in a constructible universe without being aware that this is the case. ${ }^{42} \mathrm{He}$ argues that the constructible universe largely equals ... finitude, ${ }^{43}$ i.e. a modern finitude where the finite is defined (here) as a set that can be 'covered' by a constructible set with the same cardinality as the former. ${ }^{44}$ Badiou asserts that this modern form of finitude is one of 'movement and innovation,' as opposed to the classical finitude of 'stability and repetition;'45 nevertheless it represents a return to the figure of oppression, to the normalization of the one, and a closure of thought to the realm of actual infinity. Such 'finitude' is precisely what Badiou rejects.

\section{Independence and dissatisfaction}

The axiom system (ZFC) itself has been in crisis since 1963 when Paul Cohen demonstrated that the most basic problem of set theory - that of Cantor's continuum hypothesis - was not solvable on the basis of the ZFC axioms; it can neither be refuted nor proven from the axioms of set theory, it is an independent statement. ${ }^{46}$ This result established the impossibility, within ZFC, of determining the type of multiplicity of the continuum (which corresponds to the power-set of the very first infinity, i.e. all the subsets constituted from whole numbers); set theory could not determine "the measure of the set of parts of an infinite set," or in Badiou's metaontological terms, "the excess of the power of the state with respect to that of its situation." ${ }^{47}$ Easton's theorem (1970) extended this result

\footnotetext{
$41 \quad$ Alain Badiou, L'Immanence des Vérités, Fayard, Paris 2018.

42 Terence Blake, “My Path Through Badiou's The Immanence of Truths”, available at: https:// terenceblake.wordpress.com/2018/10/06/my-path-through-badious-the-immanence-oftruths.

43 Jana Berankova, Presentation at the Graduate Workshop with Alain Badiou on The Immanence of Truths, November 13, Columbia University, New York 2019.

44 Jana Berankova, “The attributes of the absolute and Alain Badiou's response to Spinoza”, in Sometimes We Are Eternal, ed. J. N. Berankova and N. Hussey, Suture Press, Lyon 2019, pp. 174-175.

45 Terence Blake, "Badiou's The Immanence of Truths: Introduction (sketch)", available at: https://terenceblake.wordpress.com/2017/01/19/ badious-the-immanence-of-truths-introduction-sket/

46 Woodin, “Generalizing Gödel’s Constructible Universe: Ultimate L”.

47 Badiou, Being and Event, p. 275.
} 
and established the "quasi-total errancy of the excess of the state over the situation," in that it is consistent with ZFC that the power-set could be any cardinal as immense as you like, provided that it is a successor. ${ }^{48}$

Cohen's method of forcing ushered in a new age of 'freedom' from the restricted formalization assumed by the constructible universe; it exposed the formal independence of not just the continuum hypothesis, but also the axiom of constructibility (Gödel's constructible universe), from the set-theoretical framework ${ }^{49}$ - it inherently implied the non-obligation of conservatism. In the immediate term, however, the focus was on the unquantifiable excess of the infinite power-set itself, rather than on the implication of crisis for ZFC, owing to such independent statements. The recognition of the "exorbitant excess," the "innumerable injustice," implied by the almost-total un-measure of the state with respect to the situation,,$^{50}$ seems to underlie the general dissatisfaction prevailing in the 1960 's \& '70's and articulated against the state - whether in the domain of mathematics itself, or in the domains of art, or love, or politics.

\section{Incoherence and disorientation}

But today it's a question of credibility with respect to the capacity of set theory to deliver a coherent framework for infinite multiplicities. The intractability of the independence phenomenon due to Cohen's method of forcing, still unresolved more than fifty years later, challenges the foundational issues of truth in set theory (ZFC) itself, and raises the question of whether the continuum hypothesis has a truth value at all, or even whether one can "coherently talk of the realm of the infinite." ${ }^{11}$ Hugh Woodin adds that the modern significance of Scott's theorem - in light of significant advances in large cardinal theory since then establishes that the axiom of constructibility is false, i.e. that $\mathrm{V} \neq \mathrm{L}$, but he acknowledges that this claim is not universally accepted.52 By Jensen's dichotomy theorem, ${ }^{53}$ both hypotheses (i.e. $\mathrm{V}=\mathrm{L}$, and $\mathrm{V} \neq \mathrm{L}$ ) are completely valid in con-

\footnotetext{
Ibid, p. 280.

49 Woodin, "The Transfinite Universe".

50 Badiou, Being and Event, p. 282.

51 W. Hugh Woodin, "The Realm of the Infinite”, in Infinity. New Research Frontiers, ed. M. Heller and W. H. Woodin Cambridge University Press, Cambridge 2011, pp. 89-118.

52 Woodin, "The Transfinite Universe".

53 The Jensen dichotomy theorem shows that $\mathrm{V}$ must be either very close to $\mathrm{L}$ or very far from $\mathrm{L}$. Refer to Woodin, “In Search of Ultimate-L, the $19^{\text {th }}$ Midrasha Mathematicae Lectures”, p. 2.
} 
temporary mathematics, which contributes to the ambiguity of set theory. The prevailing incoherence of the frame of reference for thinking the infinite (or the crisis of formalization) coincides with contemporary widespread disorientation as manifested in dissatisfaction with society, mental ill-health, troubled youth, popular frustration, a feeling of obscure disorder, lack of orientation/stability.

\section{Platonism, pluralism, and the skeptic}

Set theory's contemporary indeterminacy undermines its candidacy as an absolute referent. As such, two major contradictory orientations arise; the universe view (or Platonism), and the multiverse view (or pluralism), together with a third: the reactionary orientation of the skeptic.

The universe view (or Platonism) holds the conviction that there is a unique absolute background concept of set, realizable in the corresponding absolute set-theoretic universe, $\mathrm{V}$, in which every assertion has a definite truth value, i.e. that quantitative infinity is rationally thinkable in a coherent framework. Questions such as the continuum hypothesis and others have definitive final answers, and it is considered that the pervasive independence phenomenon is due to an insufficiency of the theory in finding the truth, rather than about truth itself because the independence of a statement from ZFC tells little about whether it holds or not in the universe. ${ }^{54}$ With regard to the continuum hypothesis, Gödel wrote that "it must be either true or false ... and its undecidability from the axioms as known today can only mean that these axioms do not contain a complete description of reality." ${ }^{55}$ For Hugh Woodin, also Platonist, this undecidability is "perhaps tolerable on a temporary basis during a period of axiomatic discovery but it certainly cannot be the permanent state of affairs. ${ }^{{ }^{6} 6} \mathrm{He}$ also considers that, based on set theoretical work (his own and others), "there is the very real possibility that we can find a new optimal axiom (from structural and philosophical considerations) that prevents us from undecidability of some important properties of set. In which case, we will have returned, against all the odds or reasonable expectation, to the view of truth for set theory that was present

54 Joel David Hampkins, “The Set-Theoretic Multiverse: a Natural Context for Set Theory”, (MR2857736 (2012h:03002)), based on a talk given by the author at the Philosophy of Mathematics Conference (New York University, April 2009).

55 As quoted by Wolchover in "To Settle Infinity Dispute, a New Law of Logic”.

56 Woodin, "Strong Axioms of Infinity and the Search for V". 
at the time when the investigation of set theory began." ${ }^{57}$ Alain Badiou writes: "By saying that set theory constitutes an absolute reference, I am assuming that there exists a system of axioms, incompletely discovered as yet, which defines the universe $\mathrm{V}$... and defines it alone. In other words, no important, significant, useful property of sets will remain undecidable once we have been able to fully identify the axioms." ${ }^{58}$

The opposing multiverse view (or pluralism) considers that there are many distinct concepts of set, each realized in their corresponding universes which, in turn, exhibit diverse truths. Its adherents argue that we may prefer some universes to others, and that there is no obligation to consider them all as somehow equal. Here, the continuum problem is already settled, having a different answer in different universes, and it is considered that the Platonist's 'dream' solution of a new axiom for set theory by which the continuum hypothesis is decided, is impossible. This view does not necessarily undermine the claim that set theory serves as an ontological foundation for mathematics, but rather is directed against the claim that there is an absolute frame of reference in which set-theoretic truths are immutable. ${ }^{59}$ Absolute, of course, means not relative, and for Badiou, the current of thought corresponding to this vision is relativism. He writes: 60

Regarding the possibility that $\mathrm{V}$ could be an ontological referent, the most important group of opponents is made up of those who have given up on any referent at all and claim that a truth is never anything but relative or local ... This current of thought, suited like no other to representative democracy and cultural relativism, is the prevailing one today ... [E]ven those who acknowledge a sort of practical value in it ... have objected that the statement "there are only opinions" must be absolutely true, otherwise something other than opinions might well exist, and an absolute truth would therefore exist.

57 W. Hugh Woodin, "The Axiom of Determinacy, Forcing Axioms, and the Nonstationary Ideal”, in De Gruyter Series in Logic and its Applications, ed. W.A. Hodges, R. Jensen, S. Lemp, M. Magidor, $2^{\text {nd }}$ ed., De Gruyter, Berlin 1999.

${ }_{58}$ Badiou, “Towards a New Thinking of the Absolute”, p. 16.

59 Hampkins, "The Set-Theoretic Multiverse: a Natural Context for Set Theory".

6o Badiou, “Towards a New Thinking of the Absolute”, p. 13. 
The multiverse view - which ultimately corresponds to an a-symbolic vision since a symbolic requires an absolute referent - is dominant today so that disorientation reigns as we are cast adrift in an a-symbolic world.

The skeptic refers to the meta-mathematical position which asserts that the only meaningful existence assertions are those that can be verified in the physical universe - which certainly excludes set theory (the mathematics of infinite sets). ${ }^{61}$ According to Woodin, it is a position which denies any genuine meaning to a conception of uncountable sets and considers that set theory and its extensions do not reflect any mathematical reality - they are merely a reflection of the mathematician. ${ }^{62}$ For the skeptic, the continuum hypothesis is neither true nor false, and consistency claims (e.g. for large cardinal axioms) can never be meaningfully made, because the entire concept of the universe of sets is a complete fiction; as such, this view is simply a rejection of the infinite altogether. ${ }^{63}$ For example, taking a view originally espoused by Aristotle, Stephen Simpson ${ }^{64}$ argues that actual infinity doesn't really exist and so it should not so readily be assumed to exist in the mathematical universe. As reported by Natalie Wolchover, he leads an effort to wean mathematics off actual infinity, by showing that the vast majority of theorems can be proved using only the notion of potential infinity. "But potential infinity is almost forgotten now," he says. "In the ZFC set theory mindset, people tend not to even remember that distinction. They just think infinity means actual infinity and that's all there is to it." ${ }^{95}$

The current of thought corresponding to the skeptical vision responds to the crisis of formalization (ontology's contemporary indeterminacy) with a rejection of infinity altogether, and proposes a return to finitude, i.e. to the one of hierarchy, or a traditional symbolic. One might consider that such skepticism in mathematics is analogous with the political orientation which is very obviously

${ }^{61}$ Andrés Eduardo Caicedo, reviewing Woodin's “The Realm of the Infinite”, submitted to Mathematical Reviews/MathSciNet, MR 2767235, June 26, 2012.

62 Woodin, "The Transfinite Universe".

63 Woodin, "Strong Axioms of Infinity and the Search for V".

64 Stephen Simpson is a mathematician and logician at Pennsylvania State University, USA.

65 Wolchover, "To Settle Infinity Dispute, a New Law of Logic". 
gaining traction in the contemporary world, as manifested by popular support (reflecting obscure revolt) ${ }^{66}$ of Trump, Orban, Erdogan, Modi, etc. ${ }^{67}$

\section{Contemporary assessment of set theory (ontology)}

Set theorists (today) are broadly drawn from three camps, which pursue the development and refinement of set theory from different angles: the doctrine of constructibility (originating in Gödel's constructible universe, and pursuing an inner model program for the incremental understanding of large cardinals), ${ }^{68}$ the doctrine of genericity (originating in Cohen's theory of generic extensions, and pursuing a forcing program for expanding the width of the universe of sets), ${ }^{69}$ and the doctrine of large cardinals, where the hierarchy of large cardinals, while unmoored from $\mathrm{ZFC}$, is increasingly emerging as an intrinsic, fundamental conception within set theory..$^{\circ}$ As described in Being and Event, the orientations in thought corresponding to these three doctrines, hold mutually antagonistic positions, especially with respect to the question of the state. ${ }^{71} \mathrm{But}$ in recent times perhaps, the 'universists' among them find more common cause in recognition of their shared conviction (albeit differing approaches) of the possibility of an absolute framework in which set-theoretic truths are immutable, and they continue its pursuit, often even against reasonable expectation.

Since the turn of the $21^{\text {st }}$ century, adherents of the universe view have insisted on a rational discussion and investigation based on a contemporary assessment of the facts and developments in set theory to date. For instance, they recognize that Cohen's result (1963) and its mathematical descendants have severely challenged any hope for a concise conception of the universe of sets, since it is not provided by the axioms ZFC - as has been well-documented in the (more than) 50 years since..$^{72}$ In fact Cohen's method of forcing has been vastly developed and many

66 Badiou, "Reflections on the Recent Election", Verso blog, November 15, 2016, which is a transcript of his Presentation at the University of California, November 9, Los Angeles 2016.

${ }_{67}$ These are the current (2020) democratically elected presidents of the USA, Hungary, Turkey, India, respectively - all with characteristics of proto-fascism.

68 Woodin, "In Search of Ultimate-L, the $19^{\text {th }}$ Midrasha Mathematicae Lectures".

69 Wolchover, "To Settle Infinity Dispute, a New Law of Logic".

70 Woodin, "The Transfinite Universe".

${ }_{71}$ Badiou, Being and Event, chap. 27.

72 Woodin, "Strong Axioms of Infinity and the Search for V". 
questions have been shown to be unsolvable; it's not only about the continuum hypothesis which is just a statement about an infinitesimal fragment of $\mathrm{V}^{73}$

Also, large cardinal axioms are not provable from ZFC by Gödel's $2^{\text {nd }}$ incompleteness theorem. ${ }^{74} \mathrm{~A}$ large cardinal axiom is a statement that a 'very large' infinite set with certain properties exists; these cardinals carry names such as, for example, inaccessible, weakly compact, Ramsey, measurable, strong, Woodin, superstrong, strongly compact, supercompact, extendible, huge, $₫$-huge, Reinhardt. "With the definition of huge cardinals, we approach the point of rupture presented by inconsistency," 75 but we cannot determine that point from ZFC.

All of this challenges the very conception of mathematical infinity; there is a temptation to yield, and to accept the skeptical assessment that the conception of the universe of sets is incoherent. ${ }^{76}$ The skeptic wants to reject actual infinity for the sake of certainty (ontological coherence); this represents an extreme conservatism, to which adherents of the constructible universe are also vulnerable in the face of increasing recognition, among set theorists, of 'large' large cardinals without any formal consistency. ${ }^{77}$ Yet Woodin, for example, still insists that "there are statements (predictions) which we expect to be false (or true), but there does not seem to be a coherent argument that would explain 'why' unless we adopt as meaningful the conception of a non-physical realm, a view where it makes sense to talk of the existence of at least some infinite objects. ${ }^{78}$ For Badiou, in any case, it is meaningless to propound the theory of finitude since a rational, ramified thinking of infinity exists, i.e. large cardinal theory - which is the modern theory of infinity. ${ }^{79}$ Recall that the theory of finitude (for him) extends beyond the classical form (embraced by the skeptic) to the modern form of finitude which is the constructible universe $\mathrm{L}$.

\footnotetext{
73 Woodin, “Generalizing Gödel’s Constructible Universe: Ultimate L”.

74 Ibid.

75 Badiou, Being and Event, p. 448. Badiou quoting set-theorist Thomas Jech.

76 Woodin, “Generalizing Gödel's Constructible Universe: Ultimate L”.

77 The constructible universe cannot accommodate even a measurable cardinal - which is a relatively 'small' large cardinal in the hierarchy.

78 Woodin, "The Realm of the Infinite".

79 Badiou, "Towards a New Thinking of the Absolute", p. 14.
} 
Over the last few decades it has become commonplace to doubt that an ultimate completion of set theory can be articulated, or that a natural completion will settle the continuum problem. ${ }^{80}$ The greater pressure then, is to conform to the dominant view that there can be no certainty with regard to infinity (relativism), that the arbitrariness is precisely what is so exciting about it (liberalism), and in any case the pursuit for a coherent conception of $\mathrm{V}$ goes against reasonable expectation.

\section{Forcing axioms}

Meanwhile, forcing axioms (from the doctrine of genericity) continue to extend the frontiers of mathematics - the universe of sets is extended to form a new, wider universe; a forcing axiom called 'Martin's maximum' (after the mathematician Donald Martin) discovered in the 1980's, extends the universe as far as it can go. Forcing axioms fill some problematic holes in everyday mathematics; work over the past few years (including new-found uses of Martin's maximum) by Stevo Todorcevic ${ }^{81}$ and others shows that they bestow many mathematical structures with nice properties that make them easier to use and understand. They also solve the continuum hypothesis - deeming it false by adding a new size of infinity; in the extended universe created by forcing, there is a larger class of real numbers than in the original universe defined by ZFC, which means the real numbers of ZFC constitute a smaller infinite set than the full continuum. If the point is to find the most fruitful seeds of mathematical discovery (as opposed to the grains of truth that yield the most pristine mathematical universe), then forcing axioms emerge as a possible contender for addition to ZFC. Nevertheless, according to Todorcevic, “it is difficult to justify Martin’s maximum as an axiom from a philosophical point of view; it can only be justified in terms of the influence it has had on the rest of mathematics." Woodin considers that it is a rich theory for understanding structures in classical mathematics but "it's not clear how it would lead to a better understanding of infinity," which (for him) is what set theory is about. ${ }^{82}$

8o Abstract for "The Joint Quest for Absolute Infinity and the Continuum - From Cantor to Woodin”, Series of (three) lectures by Hugh Woodin at the University of Turku, May 9-11, Finland 2019.

81 Stevo Todorcevic is a mathematician at the University of Toronto, and the French National Center for Scientific Research in Paris.

82 Paragraph paraphrased from Wolchover, “To Settle Infinity Dispute, a New Law of Logic”. 


\section{Large cardinal hierarchy}

As already mentioned, large cardinal axioms are not provable from ZFC. Nor is it known whether the existence of such sets is even consistent with ZFC, with one exception; a basic theorem proved by Kunen (1971) ${ }^{8_{3}}$ shows that the existence of a Reinhardt cardinal is inconsistent with ZFC. The proof relies on the axiom of choice, and it is not known if the existence of a Reinhardt is inconsistent with ZF (i.e. ZFC minus the axiom of choice). ${ }^{84}$ But large cardinal axioms can be well-ordered by their consistency strength, thus yielding the large cardinal hierarchy. ${ }^{85}$ Also, they can decide some of the problems which are unsolvable from ZFC alone, for example, the existence of a measurable cardinal implies that the universe of sets is larger than Gödel's constructible universe. ${ }^{86}$ (This is because the existence of a measurable cardinal implies the existence of Silver's $0^{\#}$ (zero sharp), ${ }^{87}$ where $0^{\#}$ is the set of true formulae about indiscernibles and order-indiscernibles in the constructible universe $\mathrm{L}$. The existence of $0^{\#}$ however, like that of a measurable cardinal, is unprovable from ZFC). ${ }^{88}$

But they cannot decide the continuum hypothesis. (This is because the continuum hypothesis can be made true or false by forcings (Cohen) which are small in the sense that they only act on the lower (infinite) levels of the cumulative hierarchy, but these small kinds of forcings do not act on the level of a measurable cardinal or beyond, therefore the existence of a measurable (or any stronger large cardinal) simply has no bearing on the truth value of the continuum hypothesis). ${ }^{89}$

83 For the actual statement of Kunen's theorem, see Akihiro Kanamori, “The Higher Infinite”, Perspectives in Mathematical Logic, Springer-Verlag, Berlin 1994. This is Ref [5] in Woodin, "The Transfinite Universe".

Rittberg, "How Woodin Changed his Mind: New Thoughts on the Continuum Hypothesis". One theory has a higher consistency strength than another, if the consistency of the former implies the consistency of the latter. The order of consistency strength in the large cardinal hierarchy is not necessarily the same as the order of the size of the smallest witness to a large cardinal axiom. For example, the existence of a huge cardinal is much stronger, in terms of consistency strength, than the existence of a supercompact cardinal, but assuming both exist, the first huge is smaller than the first supercompact.

Rittberg, "How Woodin Changed his Mind: New Thoughts on the Continuum Hypothesis". $0^{\#}$ (zero sharp) was first introduced in Silver's 1966 thesis, which was later published as: Jack H. Silver, "Some Applications of Model Theory in Set Theory", Annals of Pure and Applied Logic 3 (1/1971), pp. 45-110.

Woodin, "In Search of Ultimate-L”, p. 3.

Rittberg, "How Woodin Changed his Mind: New Thoughts on the Continuum Hypothesis”. 
Yet the development of set theory after Cohen has led to the realization that formally unsolvable problems have degrees of unsolvability which can be exactly calibrated by large cardinal axioms, which has proven to be useful. As a consequence of this calibration, it has been discovered that in many cases very different lines of investigation have led to problems whose degree of unsolvability is the same. Thus the hierarchy of large cardinals emerges as an intrinsic, fundamental conception within set theory.90

An interesting example in this context is that large cardinal axioms do not exist in the universe of number theory, yet their existence generates new truths of that universe; more precisely, assuming the large cardinals to be true, one can infer as true specific statements of number theory which arguably cannot otherwise be proven. How then can the number theorist account for these truths? The skeptic of course will object here that all one is asserting about large cardinal axioms is formal consistency, and that such consistency claims cannot be meaningfully made since the concept of the universe of sets is so 'incomplete' that it is a complete fiction. ${ }^{91}$ For so long as large cardinal axioms remain independent set-theoretical statements, this skeptical position cannot be refuted.

\section{Exploring the universe from below (the local argument)}

'Universists' however point to the increasingly stable consequences of the large cardinal hierarchy as evidence that we are on the right track towards final answers to set-theoretical questions. ${ }^{92}$ Large cardinal axioms not only fit together, but all extensions of set theory 'considered in practice' seem to be equiconsistent with large cardinal axioms; their arithmetic consequences are compatible, and (eventually) so are their projective consequences, thus providing, for example, a coherent theory of the reals (i.e. of $\mathrm{V}_{\omega+1}$ ). This is illustrated by the axiom of determinacy (an assertion about infinite games and pivotal to current research in set theory) that turns out to be equiconsistent with the assertion that there are infinitely many Woodin cardinals. ${ }^{93}$ The axiom of determinacy (with extrinsic justifications) and 'there exist Woodin cardinals' (with intrinsic justifications) are proved to coincide. "This sort of convergence of conceptually distinct do-

\footnotetext{
90 Woodin, “The Transfinite Universe”.

91 Ibid.

92 Hampkins, “The Set-Theoretic Multiverse: a Natural Context for Set Theory”.

93 Caicedo, reviewing Woodin's "The Realm of the Infinite".
} 
mains is striking and unlikely to be an accident," as Peter Koellner ${ }^{44}$ wrote in 2006.95 Yet despite these successes, with the amount of mathematical effort and development which was required - which yielded the correct axioms for a certain part of the universe of sets, i.e. $V_{\omega+1}$ (in which the real numbers appear), and noting that this is just an infinitesimal fragment of the universe of sets $\mathrm{V}$, then the prospects for understanding $V$ itself to this same degree (or even just $V_{\omega+2}$ in which all sets of reals appear, and which would reveal whether the continuum hypothesis is true) seem daunting. ${ }^{96}$

\section{Probing the 'whole' universe of sets (the global argument)}

Taking another track, the successes of the inner model program (from the doctrine of constructibility) were encouraging, and led to the realization that the large cardinal hierarchy is a very 'robust' notion. ${ }^{97}$ The inner model program is the detailed study of large cardinal axioms, by seeking generalizations of the definition of the axiom of constructibility (Gödel) which are compatible with these axioms (such as the axioms for measurable cardinals and beyond), ${ }^{98}$ i.e. by enlarging the constructible universe (denoted by L) to accommodate targeted large cardinal axioms. The axiom of constructibility, i.e. $\mathrm{V}=\mathrm{L}$, severely limits the nature of infinity, but the constructible universe L, does have the benefit of being pristine and analyzable (unlike the cumulative hierarchy of sets V), and enlargements of L, being L-like, offer the same advantage. Inner models, i.e. enlargements of L, are constructed using both constructible elements and extender elements as defining parameters, where an extender is derived from the 'elementary embedding' which is closely linked to the large cardinal under consideration. ${ }^{99}$ Large cardinals can be defined in terms of elementary embeddings, i.e. an embedding of $\mathrm{V}$ itself into some inner model $\mathrm{M},{ }^{100}$ and extenders are non-trivial fragments of the elementary embedding. ${ }^{101}$ More precisely, one

94 Peter Koellner is a philosophy professor specializing in mathematical logic at Harvard University.

95 As quoted by Zhaokuan Hao, (Fudan University, China) in "Gödel's Program and Ultimate L”, Presentation at the National University of Singapore, September 2017.

96 Woodin, "Strong Axioms of Infinity and the Search for V".

97 Woodin, "The Transfinite Universe”.

98 Ibid.

Rittberg, "How Woodin Changed his Mind: New Thoughts on the Continuum Hypothesis". Where M is a transitive model of ZFC containing all the ordinals, and an elementary embedding is a function (not the identity) between models which preserves truth. Ibid.

101 Woodin, "The Transfinite Universe”. 
has to require that the large cardinals of the inner models which constitute the solution have some form of ancestry in the large cardinals of V. As such, the extender models are constructed as refinements of $\mathrm{V}$, which preserve enough extenders from $\mathrm{V}$ to witness that the large cardinal axiom holds. ${ }^{102}$

By the year 2000, the inner model program had been unconditionally extended to the level of Woodin cardinals - which are limits of strong cardinals, and conditionally extended to the level of superstrong cardinals. ${ }^{103}$ But the incremental nature of the program seems to be an absolutely fundamental aspect: each new construction of an enlargement meeting the challenge of a specific large cardinal axiom comes with a theorem that no stronger large cardinal axiom can hold in that model. Since it's very unlikely that there could ever be a strongest large cardinal axiom, this methodology seems unlikely by its very nature to yield an ultimate enlargement of the constructible universe, i.e. to ever succeed in providing the requisite axiom for clarifying the conception of the universe of sets..$^{104}$ The pursuits for a new axiom for set theory from below (analyzing the set-theoretic universe fragment by fragment) looked daunting, and from above (a form of extension of ZFC based on the whole universe) seemed hopeless. ${ }^{105}$

\section{Then something happened...}

Circa 2010 the situation changed dramatically, with the "remarkable and completely unexpected" discovery within the inner model program, that at a specific, critical stage in the hierarchy of large cardinal axioms, there is a breakaway point: at the level of one supercompact cardinal, the inner model construction must yield an enlargement which is compatible with all stronger large cardinal axioms, i.e. it must yield an ultimate enlargement of the inner model L. ${ }^{106}$ The requirement for enough suitable extenders from $V$ to witness that the supercompact cardinal holds, necessarily must generate 'phantom' witnesses (extenders) for all large cardinals stronger in the hierarchy. ${ }^{107}$ This is now formulated in the

\footnotetext{
102 Ibid.

103 Woodin, "In Search of Ultimate-L", p. 1.

104 Woodin, "Strong Axioms of Infinity and the Search for V".

105 Rittberg, "How Woodin Changed his Mind".

106 Woodin, "Strong Axioms of Infinity and the Search for V".

107 Woodin, "The Transfinite Universe”.
} 
'universality theorem. ${ }^{{ }^{108}}$ If such an inner model could be found, then it would accommodate all large cardinals (that are consistent with ZFC), which amounts to a paradigm shift in the whole conception of inner models. ${ }^{109}$ Is this not a mathematical event?

The entire framework for the inner model program was transformed from a program for the incremental understanding of large cardinals into a program for perhaps understanding $\mathrm{V}$ itself, and it led to the isolation of a candidate for an axiom that $\mathrm{V}$ is an ultimate version of $\mathrm{L}$. W. Hugh Woodin is on the brink (in a decadal sense) of demonstrating a transcendent version of Gödel's axiom of constructibility for the universe of sets; but where Gödel's axiom is minimal (i.e. the mimimum possible universe of sets containing all ordinals), Woodin's axiom is a maximal statement about the nature of the universe of sets. Everything now hinges on the fate of the 'ultimate-L' conjecture which, if true, provides an absolutely compelling case that $\mathrm{V}=$ ultimate-L. ${ }^{110}$

\section{Strategic-extender models}

The various approaches to inner model theory have to be fundamentally altered to provide the solution to the inner model problem for one supercompact cardinal. ${ }^{111}$ The ultimate-L program introduces a new class of model for $\mathrm{V}-\mathrm{a}$ different, previously unknown class of extender model called the strategic-extender models, which can no longer be layered (as in the non-strategic case); ${ }^{112}$ based on the strategic-extender models, one can formulate the axiom, $\mathrm{V}=$ ultimate-L, without referring to the detailed fine-structure theory of these models, or even using the definition of the structures yielding the levels of these models. The point (here) is that, in the context of a proper class of Woodin cardinals, there are naturally defined approximations to ultimate- $\mathrm{L}$ and the collection is rich enough to make a definition of the axiom, $\mathrm{V}=$ ultimate- $\mathrm{L}$, possible without specifying the detailed level-by-level definition of ultimate-L. Woodin notes that

\footnotetext{
108 Woodin, “Generalizing Gödel’s Constructible Universe: Ultimate L”.

109 Rittberg, "How Woodin Changed his Mind".

110 Woodin, "Beyond the Age of Independence by Forcing," Presentation at the Chinese Mathematical Logic Conference”, May 20, 2017.

111 Woodin, "In Search of Ultimate-L”, p. 1.

112 Ibid, p. 93.
} 
this situation is analogous to being able to formulate the axiom, $\mathrm{V}=\mathrm{L}$, without specifying the definition of L. ${ }^{113}$

Strategic-extender models were developed by generalizing on the earlier success in understanding $\mathrm{V}_{\omega+1}$ and the projective sets - which provided a good theory of the reals (assuming the existence of Woodin cardinals). They make use of the class of all hereditarily ordinal definable (HOD) sets, i.e. the class containing all those sets which are definable from ordinal parameters. ${ }^{114}$ Originally defined by Gödel, ${ }^{115}$ Woodin gives an equivalent reformulation of the class HOD which highlights it as some sort of merge of the definitions of the cumulative hierarchy $\mathrm{V}$ and of the constructible universe L. For the power-set in L, the subset is logically definable from parameters in the set, whereas in HOD, the subset is definable without parameters. He also notes here that there is a remarkable theorem of Vopenka which connects HOD and Cohen's method of forcing, ${ }^{116}$ and which illustrates why Cohen's method is so central in set theory (and for reasons other than simply establishing independence results). ${ }^{117}$

\section{Ultimate-L program}

The program to prove the ultimate-L conjecture is a 4-stage project. Stage 1 has been completed ( 2013) and it survived its first critical test; this was the construction of an L-like weak extender model for the finite levels of supercompactness. Then, "in an unexpected twist," Woodin reported, "the remaining three stages collapsed into a single final stage, and subsequent analysis has provided the key clues as to how to proceed." ${ }^{118}$ With many evidences leaning toward a positive answer for the ultimate-L conjecture, Woodin is quite confident of the outcome. However, as he wrote in March 2017, "given the series of unexpected events to date on this subject, an abundance of caution seems prudent here." ${ }^{119}$

${ }_{113}$ Ibid, pp. 94-95.

114 Woodin, "The Transfinite Universe".

115 More precisely, the definition of the class HOD originates in remarks of Gödel at the Princeton Bicentennial Conference in December, 1946. According to Woodin, the first detailed reference appears to be Ref [8] in Ibid.

116 Theorem (Vopenka). For each set $\mathrm{G} \subset$ Ord, if $\mathrm{G} \notin \mathrm{HOD}$, then $\mathrm{HOD}_{\mathrm{G}}$ is a Cohen extension of HOD.

${ }_{117}$ Woodin, "Strong Axioms of Infinity".

${ }_{118}$ Woodin, "Beyond the Age of Independence by Forcing".

119 Woodin, "In Search of Ultimate-L", p. 3. 
As of May 2017 there was a draft of a proof and, according to Woodin (at that time), "things look promising." 120

In 2019, Woodin said that the ultimate-L conjecture reduces the entire post-Cohen debate on set theoretic truth to a single question which must have an answer - true or false, i.e. it cannot be meaningless. Either the conjecture is true, in which case the axiom, $\mathrm{V}=$ ultimate- $\mathrm{L}$, is very likely the key missing axiom for $\mathrm{V}$. Or it is false, in which case the program to understand $\mathrm{V}$, by generalizing the (local) success in understanding $\mathrm{V}_{\omega+1}$ and the projective sets, fails. ${ }^{121}$

\section{The axiom V = Ultimate-L (conjectured)}

- Large cardinal axioms can (and therefore do) exist in the universe given by ultimate-L.

This is the key new feature which sets it apart from all previous generalizations of L. Ultimate L is mathematically analyzable - in this sense it is L-like - and yields a much deeper understanding of the large cardinal axioms; it identifies more precisely the transition for large cardinal axioms from the possible to the impossible (i.e. the demarcation of consistent and inconsistent sets), and provides a framework for a continuing evolution in the understanding of this transition. ${ }^{122}$ One obtains a new generation of inconsistency results for the large cardinal hierarchy (in the setting where the axiom of choice fails) which includes a mild strengthening of Reinhardt cardinals, and also Berkeley cardinals. ${ }^{123}$

- The conjectured axiom affirms the ZFC axiomatic, and in particular the axiom of choice.

It recognizes all large cardinal axioms (both known, and those yet to be discovered) consistent with ZFC, but will eliminate essentially all the large cardinal axioms known to contradict the axiom of choice. ${ }^{124}$ For example, the existence of

\footnotetext{
${ }^{120}$ Woodin, "Beyond the Age of Independence by Forcing".

${ }_{121}$ W. Hugh Woodin, “The Continuum Hypothesis", Presentation at the University of Münster (WWU), Germany, June 20, 2019.

122 Woodin, "The Transfinite Universe".

${ }_{123}$ Woodin, "In Search of Ultimate-L", p. 3.

124 Ibid.
} 
weak Reinhardt cardinals - which was already proven to contradict 'choice' by the well-known Kunen inconsistency (1971) ${ }^{125}$ - is actually refuted here. ${ }^{126}$ More fundamentally, it reveals deep connections between large cardinal axioms and proving instances of the axiom of choice. ${ }^{127}$ One also obtains, in the context of the axiom of choice, that what seem like natural generalizations of axioms of definable determinacy, are false if sufficient large cardinals are assumed to exist. ${ }^{128}$

- The continuum hypothesis is decided.

Surprisingly in fact, it holds, ${ }^{129}$ which runs counter to the intuitive expectations of notable Platonists, from Gödel, to Woodin himself, to Badiou. The type of multiplicity of the power-set is decided and with a minimum of excess; the continuum is the second infinity. In fact the axiom renders Cohen's method of forcing completely useless for establishing independence from the resulting conception of the universe of sets; ${ }^{130}$ it settles all questions about 'small' sets which have been shown to be independent by that method. This is because the axiom $\mathrm{V}=$ ultimate- $\mathrm{L}$ (or $\mathrm{V}=\mathrm{L}$, for that matter) strongly couples the width of the universe of sets V, to its height. Woodin explains that $\mathrm{V}$ has two dimensions, width and height; the height is a large cardinal issue, and the width is - how many reals do you have, i.e. how many sets of reals. $\mathrm{V}=$ ultimate- $\mathrm{L}$ binds the width to the height; if you change the width, you cannot recover the axiom without changing the height. Cohen's method changes the width, but preserves the height of $\mathrm{V}$, and that's why it is useless - it cannot affect the axiom. ${ }^{131}$

Woodin further conjectures that this axiom is true, i.e. that it will eventually be validated on the basis of accepted and compelling principles of infinity, exactly as the axiom of projective determinacy was validated, ${ }^{132}$ and the truth of which only became evident after a great deal of work, i.e. mathematical results proven

125 Kenneth Kunen, "Elementary embeddings and infinite infinitary combinatorics”, J. Symbolic Logic 36 (1971), pp. 407-413. This is Ref [7] in Woodin, “The Transfinite Universe”.

126 Woodin, "The Realm of the Infinite".

${ }_{127}$ Woodin, "Strong Axioms of Infinity and the Search for V".

${ }_{128}$ Woodin, "In Search of Ultimate-L", p. 3.

129 Woodin, “Generalizing Gödel's Constructible Universe: Ultimate L”.

130 Ibid.

${ }^{131}$ Woodin, "The Continuum Hypothesis Set Theory", Presentation at the California Institute of Technology (Caltech), February 23, 2019.

${ }_{132}$ Woodin, "Strong Axioms of Infinity and the Search for V". 
by the set theoretic community. This demonstrated (for him) that the discovery of mathematical truth is not a purely formal endeavour. ${ }^{133}$ Using the phrase "truth beyond our formal reach," Woodin maintains that there's a component in the evolution of our understanding of mathematics which is not formal, that there is mathematical knowledge which is not entirely based in proofs. ${ }^{134}$

\section{Some meta-ontological implications}

Set theory's contemporary indeterminacy - which renders the impossibility of regarding it as an absolute referent - stems from the independence of large cardinal axioms, and the undecidability of the continuum hypothesis. The non-intuitive nature of the axiom of choice, which is "without any known procedure," ${ }^{135}$ doesn't help either. ${ }^{136}$ There are many implications raised not just by the fact, but also by the manner of the resolution of these issues by the axiom $\mathrm{V}=$ ultimate-L, if indeed it is demonstrated to be true...

- The conjectured axiom, $\mathrm{V}=$ ultimate-L proposes to complete the system of axioms which define the universe $\mathrm{V}$; it offers a coherent conception of the universe of sets, presenting an unambiguous concept of the transfinite universe. Addressing the questions of independence with respect to large cardinal axioms and the continuum hypothesis, it resolves the contemporary crisis of formalization. The resulting conception of $\mathrm{V}$ is maximal and univocal, i.e. not in the least indeterminate or relative; it thereby affirms the universe (or non-pluralist) orientation, and facilitates the adoption of set theory as an absolute ontological referent.

- The skeptical assertion that $\mathrm{V}$ is meaningless (i.e. a fiction) is undermined by the articulation of a coherent and ultimately complete (but not closed) set theory. $\mathrm{V}=$ ultimate-L provides a framework for understanding and ana-

\footnotetext{
133 Rittberg, "How Woodin Changed his Mind".

134 Woodin, "The Continuum Hypothesis Set Theory".

135 Badiou, Being and Event, p. 228.

${ }_{136}$ The axiom of choice has long been subjected to criticism. It is a purely existential axiom in that it asserts the existence of a function of choice without providing any means of constructing it; it is impossible to specify any rule that might guide an infinite set of arbitrary choices. Yet it has been proved that it does not introduce any contradiction. Moreover, the axiom of choice is required to establish that every set can be well-ordered.
} 
lyzing large cardinal axioms as true axioms about the universe of sets, and no longer as independent set-theoretical statements. Large cardinal axioms exist in the universe given by $\mathrm{V}=$ ultimate- $\mathrm{L}$, which allows the number theorist, for example, to account for new truths generated in the universe of number theory by their existence. Such examples serve to ground a refutation of the skeptic.

- The universe given by $\mathrm{V}=$ ultimate- $\mathrm{L}-$ unlike the constructible universe (given by $\mathrm{V}=\mathrm{L}$ ) - recognizes all large cardinals (both known, and those yet to be discovered) consistent with ZFC, but refuses an incoherent "prodigality of being." ${ }^{137}$ The impossibility, heretofore, of determining consistency in large cardinals is surpassed, so that an axiomatic realized in the ultimate-L model transcends the fear of incoherence, the tension of uncertainty. As such, it offers a coherent way out of the constructible universe.

- $\mathrm{V}=$ ultimate-L, affirms the axiom of choice. In fact 'choice' emerges as a crucial axiom for determining formal consistency in large cardinal axioms, which therefore are no longer independent from the resulting conception of sets. For Badiou, the axiom of choice provides the precise concept of the being (as opposed to the act) of subjective intervention; he associates it with a 'principle of infinite liberty. ${ }^{9}{ }^{138}$ But in the contemporary world, freedom is generally associated with a principle of independence. Perhaps freedom will yet come to be re-defined (positively) as the expression of choice within a coherent yet unrestricted axiomatic, rather than (negatively) as the exemption (independence) from any formalization.

- Woodin's axiom affirms the truth of the continuum hypothesis. Woodin originally set out to falsify the continuum hypothesis; between 1999 and 2004, he presented three very similar yet different arguments against the continuum hypothesis, in each case, exploring the universe from below. ${ }^{139}$ But in the course of his endeavour to find the true axioms for $\mathrm{V}_{\omega+2}$ - in which the continuum hypothesis would have an answer - he was obliged to start a program in inner model theory which led to the completely unexpected discovery of

${ }_{137}$ Badiou, Being and Event, p. 283.

${ }_{138}$ Hallward, "On the Development of Transfinite Set Theory”, p. 339.

139 Rittberg, "How Woodin Changed his Mind". 
the breakaway point in the hierarchy of large cardinal axioms, and the subsequent isolation of an axiom that $\mathrm{V}=$ ultimate- $\mathrm{L}$. The truth of the continuum hypothesis is something demonstrated by this axiom, but the resulting model was not the original expectation or motivating goal.

Alain Badiou's objection to the continuum hypothesis as true (ever since he was working on what was to become Being and Event) stems from a consideration that adopting it leads to a restriction of set theory's axiomatic powers, and is therefore opposed to the principle of maximality. Yet, as he says, there were reasons for hesitating, since adopting it would introduce no contradiction, and the mere negation of the hypothesis doesn't tell us what type of infinity the continuum really is either. ${ }^{140}$ Perhaps Badiou's objection to the truth of the continuum hypothesis stems more particularly from an objection to the restrictions (minimality) of the constructible universe - which is the only situation (heretofore) which has demonstrated that truth. But Woodin's axiom is a maximal axiom for $\mathrm{V}$; it accommodates all genuine large cardinal axioms, including that of a measurable cardinal which therefore implies the existence of Silver's $0^{\#}$ and brings the doctrine of indiscernibles (generic) into the resulting conception of $\mathrm{V}$. The key point here is that ultimate- $\mathrm{L}$ is not at all $\mathrm{L}$, that in fact the inner model approach has to be altered - in a fundamental way - to provide the solution for one supercompact cardinal; ultimate-L is not simply an L enlarged to accommodate large cardinal axioms, but (having developed from a coherent theory of the reals) an $\mathrm{L}$ re-cast such that the resulting model can accommodate the reals which are overlooked (indiscernible) in L.

The normalization of the state - its minimum of excess (represented by the truth of the continuum hypothesis) ${ }^{141}$ - which was primitively achieved in the constructible universe, is accomplished here in the context of an axiomatic which is capable of challenging a much greater indeterminacy, that of consistency with respect to large cardinals; genuine large cardinals are admitted due to their (demonstrable) formal consistency and false large cardinals are refuted. It seems then that the state proves to be unduly excessive only in the absence of a coherent formal framework; beyond the narrow constructible universe (which can't admit even a measurable cardinal) and before an ultimate universe (which ad-

\footnotetext{
140 Badiou, "Towards a New Thinking of the Absolute”, pp. 17-18. 
mits all large cardinals consistent with ZFC), the specter of independent large cardinal axioms coincides with an excess of the state which is immeasurable. Once the formal framework has the capacity to identify and accommodate all genuine large cardinals, the state seems to settle into normalcy and lose its (potentially) exorbitant power of oppression.

- The axiom completely negates the ramifications of Cohen's method, leading Woodin to present a vista for set theory "beyond the age of independence by forcing." ${ }^{142}$

Badiou's maxim that "there are only bodies and languages, except that there are truths," is based on the existence of the pure theory of the multiple as an absolute ontological referent. In this respect, he writes "it is that theory, and not the general principle of the existence of truths, that it is a matter of defending here. ${ }^{\prime 143}$ Set theory as an absolute referent implies a system of axioms fully identified such that no important, significant, useful property of sets will remain undecidable; any such theory has to "banish the specter of undecidability as demonstrated by Cohen's method of forcing." ${ }^{144}$

It is noteworthy here that Alain Badiou recently remarked that he now accepts that his definition of universality - as genericity (due to Cohen) - in Being and Event is purely negative. ${ }^{145} \mathrm{He}$ added that "genericity signifies, exclusively, that universality is not reducible to properties in the situation," and that maybe it is impossible to solve the question of universality with a negative definition of this kind. He said that universality does not just consist of negative genericity, but also of something which has a form of relationship to an affirmative concept of absoluteness which he proposes in The Immanence of Truths..$^{146}$ Badiou also notes that 'elementary embedding' somehow plays a similar role to 'forcing, ${ }^{1447}$ in the sense of as a truth procedure. He says that the absolute class $\mathrm{V}$ is embed-

\footnotetext{
${ }_{142}$ Woodin, "Beyond the Age of Independence by Forcing".

143 Badiou, "Towards a New Thinking of the Absolute”, p. 13.

144 Woodin, "Strong Axioms of Infinity".

145 Badiou, Presentation at the Graduate Workshop on Being and Event, Columbia University, New York, October 24, 2017, subsequently published in Sometimes We Are Eternal, p. 58.

146 Badiou, referring to the English translation (yet unpublished) of L'Immanence des Vérités.

147 As reported by Berankova, in "The Immanence of Truths: the Absolute between the Singular and the Universal”.
} 
ded in one of its 'attributes' (Spinozist notion), i.e. in the transitive subclass M, which is thereby transformed into a model of $\mathrm{V}$. There is a relation between $\mathrm{V}$ and $\mathrm{M}$ but this is not the identity, i.e. $\mathrm{V}$ will remain different from the attribute $\mathrm{M}$ and contain sets that we cannot find in M. Thus, to say that a 'truth' is absolute does not mean that a 'truth procedure' is absolute; rather, the absolute is embedded in its attribute.

Ultimate-L - with strategic-extender models and the class HOD - seems to embrace these truth procedural conditions. The subset in HOD is definable without parameters, and HOD is connected to Cohen's method of forcing (Vopenka), so it seems that forcings are somehow already inscribed in ultimate-L giving a widening of $\mathrm{V}$. But this widening is strongly coupled with a heightening of $\mathrm{V}$ to the level of a supercompact cardinal and (thus) beyond, yielding an inner model which is very 'close' to V.

Forcing, i.e. the Cohen symptom of a sort of legal insubordination to a restricted (conservative) formalization - which is effective and necessary to demonstrate the insufficiency of ZFC - does not itself propose a solution to the crisis (of ZFC) which it initiated, but the indiscernibles which it indicates must be incorporated in any such solution. It only becomes redundant as an intervention when the formalization is sufficient. This is also the case with the 'attributes of the absolute,' i.e. large cardinals, which are indicated by the procedure of elementary embedding.

Alain Badiou has not written about ultimate-L, but then he generally does not write about what is only conjecture in set theory - he waits for results and their establishment among the set theoretical community. Woodin's axiom however seems to present the possibility of a new framework for infinite thought which is universally consistent in the sense indicated by Badiou; it completes a system of axioms which define a model which is very 'close' to $\mathrm{V}$ with the capacity to accommodate all of the reals, together with all large, demonstrably consistent 'attributes of the absolute' (large cardinal axioms). It seems to embrace a principle of maximality, ${ }^{148}$ and it affirms a 'principle of infinite liberty' (axiom of choice).

${ }_{148}$ This is in the sense that "any intellectual entity, whose existence can be inferred without contradiction from the axioms that prescribe it, exists by that very fact," Badiou, "Towards a New Theory of the Absolute", p. 11. 


\section{Implications for the symbolic, for the subject}

The argument presented in this paper is that humanity's symbolic organization, or a symbolic, requires a credible ontological referent. The breakdown of the hierarchical symbolic (of tradition) accompanied the ruin of the ontological supposition - of the being of the one - on which it relied. The modern revelation of the pure multiplicity of being as such cannot be undone. A new symbolic (if such is possible) has to recognize the non-being of the one, which means that it can only be non-hierarchical, which is to say, egalitarian. An egalitarian symbolic therefore requires a credible ontology of pure (infinite) multiplicity as referent; mathematical set theory is proposed (Badiou).

In Being and Event, Badiou wrote that metaontology "serves as an unconscious framework for every orientation in thought." 149 In this respect, the commonplace doubt that an ultimate completion of set theory can be articulated, corresponds to a general conviction of impossibility - with respect to an egalitarian symbolic which has dominated since the 1980's; such a conviction equates a symbolic solely with hierarchy, and resigns itself to (or lauds) the reign of the a-symbolic, (unless it attempts a retrogression to hierarchy).

But set theory - with the axiom $\mathrm{V}=$ ultimate-L (conjectured) - now affords the real possibility of a coherent, ultimately complete, and therefore credible, ontology of multiplicity. As such it proposes the possibility of an egalitarian symbolic. This is not to suggest that an abstract formalization in itself constitutes a concrete new symbolic, but a coherent ontology of multiplicity is an a priori requirement, i.e. a condition of possibility. The articulation - even as conjecture - of a coherent, rational thinking of infinite multiplicities challenges the dominant conviction of impossibility with respect to an egalitarian symbolic; ${ }^{150}$ it re-opens the question of a symbolic for an age of multiplicity. It implies that the idea of an egalitarian symbolic may be more than just a utopian dream.

149 Badiou, Being and Event, p. 282.

${ }^{150}$ It is of course still quite possible that ultimate-L will fail, and that an optimal axiom (or otherwise concluding axioms) for $\mathrm{V}$ will eventually take a form other than that of an inner model. Nevertheless, the significance of the supercompact cardinal and the universality theorem cannot be ignored. 
This can modify, or even flip, a subjectivity; a wishful orientation (unfounded desire), or even a hopeless one, has new reason to hope (desire combined with expectation). A condition of possibility (as opposed to impossibility) gives a subjective motivation to act (rather than hopelessly react) in the concrete world. Ontology may indicate how to proceed: such is Badiou's endeavor, with the adoption of forcing (in Being and Event) and elementary embedding (in L'Immanence des Vérités) as the being of truth procedures. It is by such "arduous and protracted procedures" that "the new pulls itself away from the old." ${ }_{151}$ But the advance from doubt, or beyond conviction, to reasonable expectation that we can have access to a 'place' of thinking where such truth procedures can be decided, gives impetus to the subject to pursue them in the objective world, whenever chance arises, or the 'event' happens.

More speculatively (and this is an impressionistic response to accounts of the remarkable developments in set theory by Hugh Woodin and colleagues), ontology might even suggest that recent phenomena such as the generation of mass testimony ('target witnesses') by activists in, for example, the 'Me Too' or the 'Black Lives Matter' movements, to challenge the inherent male/white/power bias in the existing legal, social and economic systems, will have effect. Or that the advocation of 'choice' by activists, for instance for same-sex marriage or abortion, is valid. More tantalizingly, the deep awareness of the requirement for social and economic justice by contemporary (genuine) climate activists, ${ }^{152}$ suggests the inadvertent generation of non-targeted or 'phantom' witnesses. All of these orientations have their correspondences in (speculative) ontology in the present moment.

Moreover, the development of the axiom $\mathrm{V}=$ ultimate- $\mathrm{L}$ demonstrates how the unexpected discovery (encapsulated here in the universality theorem) can change everything. It harnesses and combines the efforts of the 'universists' in the three camps of set theory, i.e. the inner model program, the generic and the large cardinal doctrines, using the resources of all three but privileging none. Those aspects of mathematical truth discovered separately in each of the three

${ }^{151}$ Zachary Luke Frazer in the introduction to Badiou, The Concept of Model, re.press, Melbourne 2007, p. xvi.

152 This is captured by Naomi Klein in "This Changes Everything: Capitalism vs. the Climate" (Simon and Schuster, New York 2014) - again, an intriguing title. 
doctrines are addressed and deployed, which suggests that in other domains perhaps those of a shared conviction, but opposing methods, might engage with each other's work.

\section{The subject and reversal of exile}

Before devising the mathematical ontology, Alain Badiou wrote a theory of the subject (1982). ${ }^{153}$ While he subsequently revised his thinking, ${ }^{154}$ some of those teachings have resonance here; in particular, his comparison of the subjective figures in Greek tragedy according to Sophocles (in Antigone), and to Aeschylus (in the Oresteia): ${ }^{155}$

In Antigone the theme is 'reversal' by which the way of the new is barred; it is not governed by any new right. The crucial point is the retrogression towards the origin. This is native reversal, reversal from the formal (what is learned) to the originary native form. It leaves no way out for the subject (Antigone) - wandering below the unthinkable - other than death. This subjective figure must always prevail in times of decadence and disarray.

Such a subjective figure seems appropriate for our times; it captures the general disorientation which prevails under the triumphant reign of the a-symbolic, with no prospect for any new right (a symbolic in an age of multiplicity) but only the retrogression to finitude by which the way of the new - actual infinity - is barred. This leaves no way out for the subject other than nihilism.

In the Oresteia the theme is the 'rupture' that allows for the advent of the new; it is a new coherence instituted by the interruption of the repetitive series that made up the whole previous social order. The key point is the interruption of the power of the origin. Orestes (the subject) demands a discussion based on facts; he stands firm and does not give in to the murderous seduction of the Erinyes. There is no return to order, and the subject is prepared to sustain exile, exile-without-return. Reversal of exile will not take place without the re-composition of a different

153 Badiou, Théorie du Sujet, Éditions du Seuil, Paris 1982.

154 Badiou, Logics of Worlds, especially the "Formal Theory of the Subject”, pp. 43-89.

155 Badiou, Theory of the Subject, Bloomsbury Academic, London and New York 2013, pp. 161-168. 
order - which is not simple. Neither will it take place without the structural anchorage of the native - indeed it is from the materialistic impasse of the latter that the practical existence of the former proceeds.

Here the subjective figure seems to correspond to the universe orientation (or faithful subject) with respect to the situation of set theory; it captures the interruption (the Cohen event) of the repetitive series $(\mathrm{V}=\mathrm{L})$ that made up the previous natural order. There is no return to order, and the subject is prepared to sustain exile without return (set theory's indeterminacy).

After more than 50 years of roaming (sustained exile) - refusing the native reversal of the skeptic, and overcoming the exile-without-return of the generic (due to Cohen) - set theory now affords the possibility, not of a return to order, but the recomposition of a different order $(\mathrm{V}=$ ultimate- $\mathrm{L})$. It is only the insistence of the interruption (forcing/generic) which, in the end, allows for the advent of a new right capable of completely recomposing the whole logic of the decision. Risking the hyperbole of understatement, this is not simple. Moreover, the reversal of exile will not take place without the structural anchorage of the native ("the anchoring of the ordinals in being" ${ }^{156}$ ); ultimate-L, as a new, consistent universe capable of accommodating all cardinals, is still structurally anchored in $\mathrm{L}$ which is the minimum possible universe of sets containing all ordinals, but with $\mathrm{L}$ re-shaped, re-composed. Indeed it is from the materialistic impasse of the latter (i.e. the constructible power-set is never the set of all subsets of the set), that the practical existence of the former proceeds (by generalizing the success in understanding the reals, i.e. $\left.\mathrm{V}_{\omega+1}\right)$. Finally - faithful to the conviction that "even though we have to return, and it is this return that makes the subject [set theory] - there can arise an enlightened overcoming of what no longer entails any return." 157

\section{References}

Acheronta, Movebo, “Towards a New Thinking of the Absolute”, Crisis and Critique 1 (2/2014)

Badiou, Alain, Being and Event, trans. Oliver Feltham, Continuum, London and New York 2007

156 Badiou, Number and Numbers, p. 83.

157 Badiou, Theory of the Subject, p. 168. 
- L'Immanence des Vérités, Fayard, Paris 2018

- Logics of Worlds, trans. Alberto Toscano, Continuum, London and New York 2009

- Manifesto for Philosophy, trans. Norman Madarasz, SUNY Press, Albany, New York 1996

- Number and Numbers, Polity Press, Cambridge UK and Malden USA 2008

- Presentation at the Graduate Workshop on Being and Event, October 24, Columbia University, New York 2017

- “Reflections on the Recent Election”, Verso blog, November 15, 2016

- Theoretical Writings, trans. Ray Brassier and Alberto Toscano, Bloomsbury Academic, London and New York 2014

- The Concept of Model, trans. Zachary Luke Fraser and Tzuchien Tho, Re.press, Melbourne 2007

- Théorie du Sujet, Éditions du Seuil, Paris 1982

- Theory of the Subject, trans. Bruno Bosteels, Bloomsbury Academic, London and New York 2013

- “True and False Contradictions of the Crisis”, Verso blog, May 29, 2015

Berankova, Jana Ndiaye, “The Immanence of Truths: the Absolute between the Singular and the Universal”, Presentation at the Conference "Thinking the Infinite", April 11, Prague 2018

- "The Attributes of the Absolute and Alain Badiou's Response to Spinoza”, in Sometimes, We Are Eternal, Suture Press, Lyon 2019

- Presentation at the Graduate Workshop with Alain Badiou on The Immanence of Truths, November 13, Columbia University, New York 2019

Blake, Terence, “Badiou's The Immanence of Truths: Introduction (sketch)”, available at: https://terenceblake.wordpress.com/2017/01/19/badious-the-immanence-of-truthsintroduction-sket

- "My Path Through Badiou's The Immanence of Truths", available at: https://terence blake.wordpress.com/2018/10/06/my-path-through-badious-the-immanence-oftruths

Caicedo, Andrés Eduardo, “Review of Woodin's ‘The Realm of the Infinite”, submitted to Mathematical Reviews/MathSciNet, MR 2767235, June 26, 2012

Cheng, Eugenia, Beyond Infinity, Profile Books, London 2018

Hallward, Peter, Badiou: A Subject to Truth, University of Minnesota Press, Minnesota 2003

Hampkins, Joel David, “The Set-Theoretic Multiverse: a Natural Context for Set Theory”, (MR2857736 (2012h:03002))

Hao, Zhaokuan, “Gödel's Program and Ultimate L”, Presentation at the National University of Singapore, September 2017

Kanamori, Akihiro, “The Higher Infinite”, in Perspectives in Mathematical Logic, Springer-Verlag, Berlin 1994 
Klein, Naomi, This Changes Everything: Capitalism vs. the Climate, Simon and Schuster, New York 2014

Kunen, Kenneth, "Elementary embeddings and infinite infinitary combinatorics”, Journal of Symbolic Logic 36 (1971)

Rittberg, Colin J, "How Woodin Changed his Mind: New Thoughts on the Continuum Hypothesis”, Archive for History of Exact Sciences 69 (2016)

Silver, Jack H, "Some Applications of Model Theory in Set Theory”, Annals of Pure and Applied Logic 3 (1/1971)

Encyclopedia.com, Symbolic, the (Lacan), available at: https://www.encyclopedia. com>psychology >symbolic-lacan

Wolchover, Natalie, “To Settle Infinity Dispute, a New Law of Logic”, Quanta Magazine, November 26, 2013 (reprinted on ScientificAmerican.com, December 3, 2013)

Woodin, W. Hugh, "Beyond the Age of Independence by Forcing”, Presentation at the Chinese Mathematical Logic Conference, May 20, 2017

- "In Search of Ultimate-L, the $19^{\text {th }}$ Midrasha Mathematicae Lectures", The Bulletin of Symbolic Logic 23 (1/2017) (DOI:10.1017/bsl.2016.34)

- "Strong Axioms of Infinity and the Search for V", in Proceedings of the International Congress of Mathematicians. Hyderabad, India 2010

- "The Axiom of Determinacy, Forcing Axioms, and the Nonstationary Ideal", in De Gruyter Series in Logic and its Applications, $2^{\text {nd }}$ edition, De Gruyter, Berlin 1999

- "The Continuum Hypothesis", Presentation at the University of Münster (WWU), June 20, Germany 2019

- "The Continuum Hypothesis Set Theory", Presentation at the California Institute of Technology (Caltech), February 23, 2019

- “The Realm of the Infinite”, in Infinity. New Research Frontiers, Cambridge University Press, Cambridge 2011

- “The Transfinite Universe”, in Kurt Gödel and the Foundations of Mathematics. Horizons of Truth, Cambridge University Press, Cambridge 2011 